BRIEF COMMUNICATION

\section{A new family of "megaphages" abundant in the marine environment}

\author{
Slawomir Michniewski ${ }^{1}$, Branko Rihtman ${ }^{2}$, Ryan Cook $^{3}$, Michael A. Jones ${ }^{3}$, William H. Wilson ${ }^{4,5}$, David J. Scanlan (D) ${ }^{2}$ and \\ Andrew Millard (iD ${ }^{6 凶}$
}

(c) The Author(s) 2021
Megaphages, bacteriophages harbouring extremely large genomes, have recently been found to be ubiquitous, being described from a variety of microbiomes ranging from the animal gut to soil and freshwater systems. However, no complete marine megaphage has been identified to date. Here, using both short and long read sequencing, we assembled $>900$ high-quality draft viral genomes from water in the English Channel. One of these genomes included a novel megaphage, Mar_Mega_1 at $>650 \mathrm{~Kb}$, making it one of the largest phage genomes assembled to date. Utilising phylogenetic and network approaches, we found this phage represents a new family of megaphages. Genomic analysis showed Mar_Mega_1 shares relatively few homologues with its closest relatives, but, as with other megaphages Mar_Mega_1 contained a variety of auxiliary metabolic genes responsible for carbon metabolism and nucleotide biosynthesis, including a NADP-dependent isocitrate dehydrogenase [Idh] and nicotinamidenucleotide amidohydrolase [PncC], which have not previously been identified in megaphages. Mar_Mega_1 was abundant in a marine virome sample and related phages are widely prevalent in the oceans.

ISME Communications; https://doi.org/10.1038/s43705-021-00064-6

\section{INTRODUCTION}

Phages, viruses that prey on bacteria, are the most abundant biological entities on Earth. Although they are ubiquitous and highly diverse components of the microbiome [1], the majority of known phages contain genomes smaller than $200 \mathrm{~kb}$ [2]. However, advances in the field of viral metagenomics led to the recent discovery of megaphages-phages with extremely large genomes ( $>540 \mathrm{~kb}$ in length). The first identified megaphages, Lak phages, contained alternatively coded genomes and were present in both animal and human gut microbiota [3]. This was followed by the identification of multiple megaphage genomes including the largest known phage genome, $735 \mathrm{~kb}$ in length, from a range of viromes across Earth's ecosystems [4]. Currently megaphages have been found in human and animal microbiomes $[3,5]$ soil and deep subsurface environments [4] and freshwater lakes [4, 6]. However, megaphages thus far have not been described from marine systems.

\section{RESULTS}

Using a combination of Illumina and MinION sequencing, three marine viral communities isolated from the western English Channel and Plymouth Sound were investigated (Supplementary Methods). This resulted in the reconstruction of 23,179 putative viral contigs (acc:ERZ2485795) with 972 high-quality draft genomes of which 367 are predicted to be complete based on MIUViG standards [7] (Table S1). These included six phage genomes with lengths $>200 \mathrm{~kb}$ and one exceptionally large 656,628 bp genome, Mar_Mega_1 (acc:OU342829.1). This genome comprised 1062 predicted genes including one tmRNA, 50 tRNAs and 1011 coding sequences. However, a combination of approaches including Blast, hmm searching and Phyre 2 analyses resulted in the function being assigned to only 268 proteins (Table S2). The large genome size of Mar_Mega_1 makes it one of the largest phage genomes assembled to date and puts it in the range of "megaphages". Comparison of the Mar_Mega_1 genomic sequence with known phages showed no significant similarity at the nucleotide level. Clustering with other phages using vContact2 suggested it is related to other megaphages (Fig. S1, Table S3). This was confirmed by a phylogeny built using the amino-acid sequence of the terminase large subunit (Fig. 1). All Lak-like megaphages formed a single clade, as was previously described [3], whilst Mar_Mega_1 formed a cluster with the largest megaphages (genome lengths $>630 \mathrm{~kb}$ ). Our newly identified phage is in a sister group to the uncultured phages LR756502 and LR745206 [4] identified from a freshwater lake in France and subsurface sample in Japan, respectively. However, the long branch lengths suggest that Mar_Mega_1 is only distantly related to these freshwater megaphages.

To further investigate the relationship of Mar_Mega_1 with its closest relatives, a core gene approach was used using parameters recommended for defining phage families [8]. All three phages share a core of only 125 genes that constitutes between 12.3\% (Mar_Mega_1) and 13.2\% (LR745206) of genes in

\footnotetext{
${ }^{1}$ Warwick Medical School, University of Warwick, Gibbet Hill Road, Coventry CV4 7AL, UK. ${ }^{2}$ School of Life Sciences, University of Warwick, Gibbet Hill Road, Coventry CV4 7AL, UK. ${ }^{3}$ School of Veterinary Medicine and Science, University of Nottingham, Sutton Bonington Campus, Sutton Bonington, Leicestershire LE12 5RD, UK. ${ }^{4}$ Marine Biological Association, The Laboratory, Plymouth, United MBA, Plymouth, UK. ${ }^{5}$ School of Biological and Marine Sciences, University of Plymouth, Plymouth PL4 8AA, UK. ${ }^{6}$ Dept Genetics and Genome

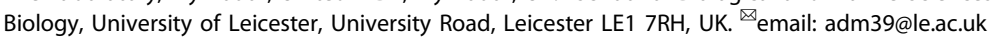

Received: 30 July 2021 Revised: 24 September 2021 Accepted: 1 October 2021

Published online: 20 October 2021 
A

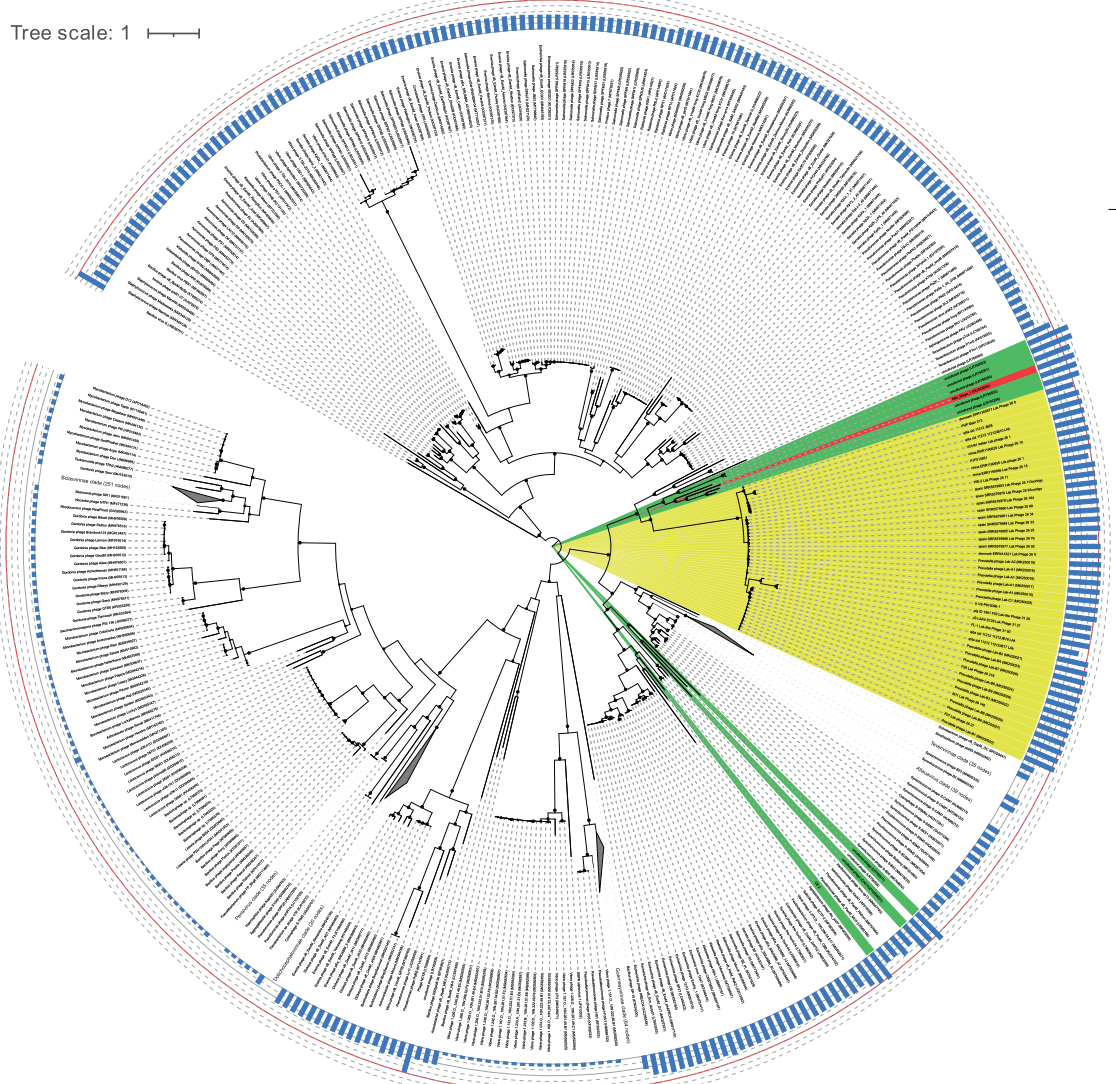

B 

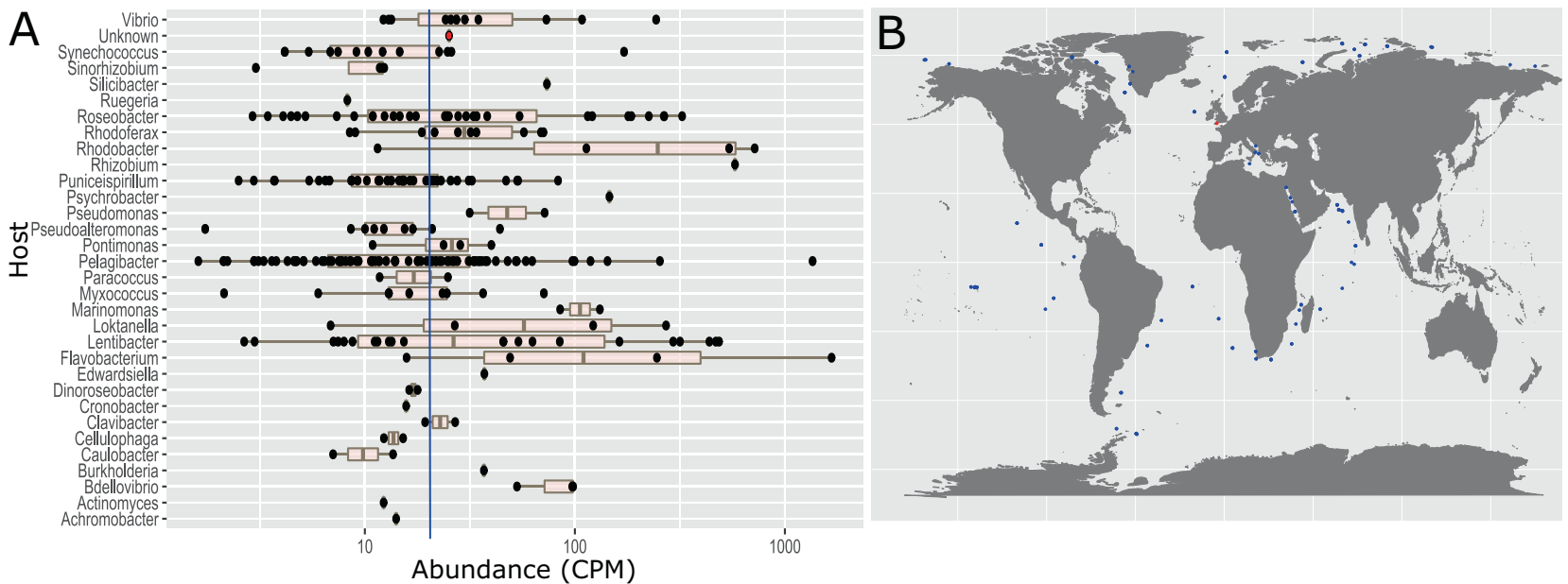

Fig. 2 Abundance and distribution of Mar_Mega_1 -like phages. A Relative abundance of vOTUs associated with known phages in the Plymouth Sound virome. Abundance is represented by counts per million. Each black dot represents a viral contig that could be associated with a known phage based on mash similarity, or clusters in the same group as a known phage using vContact2. Host information was extracted from known phages. Mar_Mega_1 is represented by a red dot (unknown host). The median relative abundance of all 269 vOTUs with similarity to known phages is denoted by a blue horizontal line. B The distribution of Mar_Mega_1-like phages. Reads from GOS and GOV2.0 were mapped against Mar_Mega_1 and 9 TARA vOTUs carrying a TerL that clustered with Mar_Mega_1. Stations are marked where read coverage was $>1 \mathrm{x}$ across $70 \%$ of the genome. Blue dots denote where Mar_Mega_1-like phages were detected and red where Mar_Mega_1 was detected.

dehydrogenase [ldh] and patatin-like phospholipase (PLP) [12] enzymes. In addition, Mar_Mega_1 possessed a putative TonBdependent receptor (SusC) which was also present in LR745206, as well as AMGs encoding putative dihydrofolate reductase, phosphoesterase and peptidase enzymes which were also found in megaphages LR745206, LR756501, LR756502, LR756503 and LR756504 (Table S2).

The presence of AMGs potentially involved in carbon metabolism in Mar_Mega_1 is consistent with previous research indicating the prevalence of AMGs responsible for carbohydrate and amino acid uptake and metabolism in model marine phage systems and viral metagenomes [13]. For example, the TonB-dependent receptor SusC might be responsible for increasing carbohydrate uptake during infection [14], whereas the NADP-dependent isocitrate dehydrogenase [Idh], an AMG which was previously detected in marine viromes [15] carries out the oxidative decarboxylation of isocitrate to aketoglutarate (aKG). aKG is a rate-determining intermediate in the tricarboxylic acid cycle and crucial for both cellular energy metabolism and as a source of glutamate and glutamine. As such, it is a central regulator affecting numerous metabolic pathways through its role in bridging carbon and nitrogen metabolism, as well as being a key signalling molecule of cellular nutrient status [16]. Thus this enzyme potentially plays an important role during the infection process. Furthermore, AMGs responsible for pyridine nucleotide synthesis such as nicotinamide-nucleotide amidohydrolase (PncC) whilst new to megaphages, have previously been found in other phages such as Vibrio phage KVP40 which encodes its own $\mathrm{NAD}^{+}$salvage pathway [17]. Moreover, the Mar_Mega_1 phage encoded dihydrofolate reductase could act two-fold by increasing the host's capacity to convert dihydrofolate into tetrahydrofolate which is essential for purine nucleotide biosynthesis or, due to similarity with a putative $d f r A 3$ antibiotic resistance gene, confer protection against diaminopyrimidine antibiotics, which are one of the most common antibiotic pollutants in marine environments [18].

This is the first time a patatin-like phospholipase (PLP) was identified within a phage genome. Although the function of PLPs is currently not clear, a role in bacterial pathogen-eukaryotic host interactions was suggested [19]. We have since been able to identify a homologue of PLP in other phages (acc: LR745206), suggesting that megaphages might increase the virulence of their putative bacterial hosts.

\section{CONCLUSIONS}

We identified the largest marine megaphage to date. Using phylogenetic and genomic analyses it is distantly related to megaphages found in other environments. Analysis of marine viromes suggests Mar_Mega_1-like phages are abundant and widely distributed in the marine environment.

\section{REFERENCES}

1. Dion MB, Oechslin F, Moineau S. Phage diversity, genomics and phylogeny. Nat Rev Microbiol. 2020;18:125-38.

2. Yuan Y, Gao M. Jumbo bacteriophages: an overview. Front Microbiol. 2017;8:403.

3. Devoto AE, Santini JM, Olm MR, Anantharaman K, Munk P, Tung J, et al. Megaphages infect Prevotella and variants are widespread in gut microbiomes. Nat Microbiol. 2019;4:693-700.

4. Al-Shayeb B, Sachdeva R, Chen LX, Ward F, Munk P, Devoto A, et al. Clades of huge phages from across Earth's ecosystems. Nature. 2020;578:425-31.

5. Crisci MA, Chen LX, Devoto AE, Borges AL, Bordin N. Wide distribution of alternatively coded Lak megaphages in animal microbiomes. bioRxiv 2021.

6. Chen L-X, Méheust R, Crits-Christoph A, McMahon KD, Nelson TC, Slater GF, et al. Large freshwater phages with the potential to augment aerobic methane oxidation. Nat Microbiol. 2020;5:1504-15.

7. Roux S, Adriaenssens EM, Dutilh BE, Koonin EV, Kropinski AM, Krupovic M, et al. Minimum information about an uncultivated virus genome (MIUViG). Nat Biotechnol. 2019;37:29-37.

8. Turner D, Kropinski AM, Adriaenssens EM. A roadmap for genome-based phage taxonomy. Viruses. 2021;13:506.

9. Brum JR, Ignacio-Espinoza JC, Roux S, Doulcier G, Acinas SG, Alberti A, et al. Ocean viral communities. Science. 2015;348:1261498-1-11.

10. Gregory AC, Zayed AA, Conceição-Neto N, Temperton B, Bolduc B, Alberti A, et al. Marine DNA viral macro- and microdiversity from pole to pole. Cell. 2019;177:1-15.

11. Roux S, Emerson JB, Eloe-Fadrosh EA, Sullivan MB. Benchmarking viromics: an in silico evaluation of metagenome-enabled estimates of viral community composition and diversity. PeerJ. 2017;5:e3817.

12. Wilson SK, Knoll LJ. Patatin-like phospholipases in microbial infections with emerging roles in fatty acid metabolism and immune regulation by Apicomplexa. Mol Microbiol. 2018;107:34-46.

13. Warwick-Dugdale J, Buchholz HH, Allen MJ, Temperton B. Host-hijacking and planktonic piracy: how phages command the microbial high seas. Virol J. 2019;1:1-13.

14. Reeves AR, D'Elia JN, Frias J, Salyers AA. A Bacteroides thetaiotaomicron outer membrane protein that is essential for utilization of maltooligosaccharides and starch. J Bacteriol. 1996;178:823-30. 
15. Hurwitz BL, Hallam SJ, Sullivan MB. Metabolic reprogramming by viruses in the sunlit and dark ocean. Genome Biol. 2013;14:R123.

16. Huergo LF, Dixon R. The emergence of 2-oxoglutarate as a master regulator metabolite. Microbiol Mol Biol Rev. 2015;79:419-35.

17. Lee JY, Li Z, Miller ES. Vibrio phage KVP40 encodes a functional $N A D^{+}$salvage pathway. J Bacteriol. 2017;199:e00855-16.

18. Felis E, Kalka J, Sochacki A, Kowalska K, Bajkacz S, Harnisz M, et al. Antimicrobial pharmaceuticals in the aquatic environment-occurrence and environmental implications. Eur J Pharmacol. 2020;866:172813.

19. Banerji S, Flieger A. Patatin-like proteins: a new family of lipolytic enzymes present in bacteria? Microbiology. 2004;150:522-5.

\section{ACKNOWLEDGEMENTS}

S.M was supported by a NERC CENTA PhD studentship. A.M was supported by MRC grants MR/L015080/1 and MR/T030062/1.

\section{AUTHOR CONTRIBUTIONS}

SM, AM and DJS conceived the work. WHW, SM and AM collected material and data. $S M, A M, B R$ and RC analysed the data. AM, DJS and MJ supervised the project. SM, DJS and AM drafted the manuscript. All authors contributed to revising and approval of the submitted work.

\section{COMPETING INTERESTS}

The authors declare no competing interests.

\section{ADDITIONAL INFORMATION}

Supplementary information The online version contains supplementary material available at https://doi.org/10.1038/s43705-021-00064-6.

Correspondence and requests for materials should be addressed to Andrew Millard.

Reprints and permission information is available at http://www.nature.com/ reprints

Publisher's note Springer Nature remains neutral with regard to jurisdictional claims in published maps and institutional affiliations.

Open Access This article is licensed under a Creative Commons Attribution 4.0 International License, which permits use, sharing, adaptation, distribution and reproduction in any medium or format, as long as you give appropriate credit to the original author(s) and the source, provide a link to the Creative Commons licence, and indicate if changes were made. The images or other third party material in this article are included in the article's Creative Commons licence, unless indicated otherwise in a credit line to the material. If material is not included in the article's Creative Commons licence and your intended use is not permitted by statutory regulation or exceeds the permitted use, you will need to obtain permission directly from the copyright holder. To view a copy of this licence, visit http://creativecommons. org/licenses/by/4.0/.

(c) The Author(s) 2021 